\title{
Employee involvement and participation in SMEs: a synthesis of extant research
}

\begin{abstract}
It is widely acknowledged that small and medium-sized enterprises (SMEs) cannot afford underutilize their workforce and owner/managers encourage ways to involve employees. In this article, we focus on what is known about formal employee involvement and participation (EIP) practice in SMEs. Based on a systematic, "aggregative" literature review (Briner and Denyer 2012; Gough et al. 2012) we identify key research on EIP in SMEs that is embedded in practice and provides utility for practitioners and policy makers. The findings not only allow us to comment briefly on the evolution of EIP research in SMEs, but to identify methodically what is known and not known about EIP practice in SMEs. We go therefore beyond the limited review provide by Sameer and Özbilgin (2014) and identify with a higher level of confidence three key directions for future academic research.
\end{abstract}

Keywords: Human resource management; Small and medium-sized firms; Systematic literature review

\section{Introduction}

Research evidence has accumulated over the past 25 years, primarily for large firms that employees and organizational culture represent the unique competitive advantage in an economy that has become increasingly service and knowledge based (Katzenbach 2000;

Corresponding author: e-mail: srohlfer@cunef.edu

Received 09 Nov 2016 - Accepted 26 Sept 2017

This is an Open Access article distributed under the terms of the Creative Commons Attribution-Non-Commercial-No Derivatives License (http://creativecommons.org/licenses/by-nc-nd/4.0/), which permits non-comercial re-use and distribution, provided the original work is properly cited, and is not altered or transformed in any way. 
Schwartz 2010; Ulrich and Ulrich 2010). Other sources of competitive advantage (e.g. access to capital, design of products, consulting advice) can be bought or copied. Thus, human resource management (HRM) practices and a changed role for the human resource (HR) department emerge as important success factors for large firms. One might argue that employees and firm culture are even more important to the success of small and medium-sized enterprises (SMEs). SMEs do not have the capacity and slack to retain employee and practices that do not contribute to performance, cannot afford to underutilize their workforce, and must rely on staff for learning, innovation and creativity (Castrogiovanni 2011).

Key elements in this discussion are the individuals that comprise the organization and the ways to involve these employee resources. While it is widely acknowledged that in SMEs HR practices do not rise to the level of functionality and formalization found in large firms, research has found that small firms do employ a mix of HR practices (Hayton 2004; Barrett and Mayson 2007).

For this article, we particularly focus on the practice of employee involvement and participation (EIP) in SMEs. There is growing evidence in the general literature that EIP is broadly necessary and beneficial for organizational longevity and success. A glut of literature considers its relationship with organizational performance, climate and commitment (Richardson et al. 2010; Peccei at al. 2010; Pyman et al. 2010), job satisfaction and industrial citizenship (Antcliff and Saundry 2009; Pyman et al. 2006), psychological contract (Guest 1998) and high-performance work systems (Bryson et al. 2007; Wood and Fenton O’Creevy 2005).

Despite its importance to firms' success and longevity, Sameer and Őzbilgin (2014) not only observe that research on EIP in SMEs is largely absent in academic studies but they also underline that EIP research must be contextualized more clearly to the SME setting. They point 
to the myriad of formal and mainly direct EIP mechanisms, the prevalence of more informal employee relations and the union absence in SMEs that taken together stimulate distinct dynamics in EIP practice compared to large organisations (Sameer and Özbilgin 2014). In fact, Sameer and Özbilgin build a case to explain why (more) EIP research in SMEs is not only stimulating and vital, but also fills gaps in knowledge. However, their approach is not guided by explicitly stated inclusion and exclusion criteria and may involve cherry picking of EIP research to support their point as they "present a general overview on important contemporary debates in the employee voice and locate it in industrial relations and human resource management literatures" (Sameer and Özbilgin 2014, 411). Sameer and Özbilgin (2014) do not claim to use explicit rigorous methods and there is the risk that articles are selectively chosen from what is available. Their overview falls short of providing an in-depth, comprehensive and balanced account of extant EIP research based on a descriptive and thematic analysis. By contrast, reviewing the available literature systematically and making the review method explicit and transparent allows us to draw conclusions with higher levels of certainty, consistency and assurance about what is known and not known about EIP in SMEs (Tranfield, Denyer, and Smart 2003; Briner and Denyer 2012).

Moreover, recent research based on qualitative case study research confirms the interplay between formal and informal practices (Cox et al. 2009; Della Torre and Solari 2013; Marchington and Suter 2013; Townsend et al. 2012). The evidence points to the important role played by informal EIP mechanisms with formal and informal EIP practice complementing each other. While academics call for more research to identify how formal and informal practices interplay with each other (Cox et al. 2009; Marchington 2015), the importance of formal EIP should not be underestimated. The empirical research clearly demonstrates that 
formal EIP techniques tend not to be fully substituted by informal practices (Townsend et al. 2012; Marchington and Suter 2013). Informality may not survive as a sustainable mechanism for employee participation in the absence of formal structures, especially if certain external or internal factors, such as market conditions or senior management philosophies change (Cox et al. 2009; Wilkinson et al. 2004) or might reach its limits and formal mechanisms are sought to ensure all employees are reached (Marchington and Suter 2013).

Against this background this article pursues the following objectives: Through the means of a systematic, "aggregative" literature review (Gough et al. 2012) we identify key research on formal EIP in SMEs that is embedded in practice and provides utility for practitioners and policy makers. Apart from mapping the EIP research based on a statistical analysis that allows us to comment briefly on the evolution of EIP research in SMEs, we carry out a thematic analysis of articles to identify more accurately what is known and not known about EIP practice in SMEs (Briner and Denyer 2012). The findings are valuable to help academics framing subsequent empirical enquiries into EIP practice.

\section{Conceptual boundaries and method}

Our aim is to evaluate of what has been found to date in empirical research on EIP in SMEs and to create an agenda to fill some empirical holes in extant research. First, we considered studies that were concerned with SMEs, i.e. enterprises that per the widely accepted definition by the European Commission employ fewer than 250 persons, apart from turnover or balance sheet total. For our study the employment size variable is decisive as it sets the scene for EIP practice at workplace level. In addition, we only consider research that focus on stand-alone independent firms i.e. that are not part of a larger conglomerate. Owner/managers in these firms have a more unfettered choice which practices to choose since they are unconstraint through 
centrally advocated and/or requested management policies and practices. More importantly, owner/managers implement EIP practices that fit the resources of the SME context while branches of larger businesses may rely on central company resources to make EIP work.

Given our focus, we considered only studies concerned with formal EIP. As commented earlier, classifications may present problems in SMEs where day-to-day interactions between employee and management tend to encourage an informal dimension to participation (Cox et al. 2009; Moore and Read 2006). Moreover, the meanings and forms EIP can take vary considerably depending on the discipline (Wilkinson et al. 2010). EIP practice usually encompasses a range of mechanisms used to involve the workforce whether undertaken directly with employees in a formal setting or indirectly through their representatives via formal ongoing bodies such as JCCs or works councils (Marchington 2015). For the literature review we adopt a pragmatic approach. While it is well established that there are important differences in the formal structures for EIP at the workplace across Europe (Fulton 2013), we consider formal EIP encompassing the practices commonly identified by researchers in the field (Eurofound 2015; Marchington and Wilkinson 2005; Wilkinson, Dundon, and Grugulis 2007). These include (a) direct communication -regular workforce meetings; regular team briefings; e-mail/intranet; management chain, notice board, newsletters-; (b) upward problem-solving - suggestion schemes, attitude surveys-; (c) representative participation -joint consultative committee, unions-; and (d) financial participation - performance-related pay, profit-related pay and share schemes.

Since our primary aim is to evaluate the prevalence of EIP in SMEs at present and to create an agenda to fill the empirical holes in current research, our systematic review aims at an aggregative review that requires a encompassing, unbiased data set of empirical studies (Gough 
et al. 2012). We therefore searched in six reference databases: (1) Ebsco's Business Source Complete, (2) ProQuest's ABI-INFORM - complete (Business), (3) Web of Science; (4) JSTOR and (5) Emerald Insight and (6) Springer Link, which were chosen from amongst others as the databases focusing explicitly on articles pertaining to the areas such as economics, business, management and sociology.

Consistent with our conceptual framework on direct and representative formal EIP the search terms used were "employee involvement", "employee participation", “employee representation", "employee voice" and "employee influence". In parallel, the search was duplicated by substituting "employee" with "worker". These terms were crossed with the search terms "SME*" and "small and medium sized firm*". Due to considerable variation in the terminology used to map the SME terrain, we also included the terms "small firm*", "small organi*", "small enterprise*”and "small business*” (Nolan and Garavan 2015).

The review was limited to scholarly, peer-reviewed journal articles, both practitioner and academics oriented. Empirical studies (either qualitative or quantitative methods) as well as conceptual papers published in English were included.

Each database was interrogated by the search terms mentioned above on June $15^{\text {th }}$ and $16^{\text {th }}$ 2016. Titles and abstracts were searched with search date and numbers returned recorded. See Table 1 for a more detailed description of the search boundaries and the inclusion and exclusion criteria.

The total number of potentially relevant studies retrieved using search strings alone was 166 , which yielded in 86 articles having removed duplications across the six databases. These were exported to Excel to create a common database, where the abstracts were further reviewed against the inclusion and exclusion criterion in an iterative process. 
Table 1. Search boundaries of the systematic literature review and the criteria for the selection of the articles

\begin{tabular}{|l|l|}
\hline \multicolumn{2}{|l|}{ Search boundaries } \\
\hline Databases & $\begin{array}{l}\text { EBSCO, ABI-INFORM, Web of Science, Jstor, Emerald, } \\
\text { Springer }\end{array}$ \\
\hline Time period covered & no time restrictions \\
\hline Type of publications & peer-reviewed articles, academic or practitioner oriented \\
\hline Language & English \\
\hline EIP concept & $\begin{array}{l}\text { "employee involvement", "employee participation", "employee } \\
\text { representation", "employee voice", "employee influence" } \\
\text { worker involvement", "worker participation", "worker } \\
\text { representation", "worker voice" and "worker influence" }\end{array}$ \\
\hline SMEs & $\begin{array}{l}\text { "SME*", "small and medium sized firm*", "small firm*”, } \\
\text { "small organi*”, "small enterprise*”, "small business*” }\end{array}$ \\
\hline
\end{tabular}

\begin{tabular}{|l|l|}
\hline \multicolumn{2}{|l|}{ Selection of articles } \\
\hline All private sector firms & Examine EIP across different sectors \\
\hline All SMEs & $\begin{array}{l}\text { Examine EIP across different types of SMEs at all stages of } \\
\text { development }\end{array}$ \\
\hline $\begin{array}{l}\text { Quantitative and qualitative empirical } \\
\text { studies }\end{array}$ & Capture all empirical evidence \\
\hline Theoretical papers & $\begin{array}{l}\text { Examine the working assumptions, conceptual underpinnings to } \\
\text { be used in the field }\end{array}$ \\
\hline Public sector firm or NGO & Exclusion criteria \\
\hline $\begin{array}{l}\text { Being a business unit of an MNCs or } \\
\text { having an affiliation to, or ownership by, } \\
\text { another organization }\end{array}$ & $\begin{array}{l}\text { Operating under different corporate governance principles } \\
\text { therefore being under the headquarters' influence on business } \\
\text { unit policies and practices }\end{array}$ \\
\hline $\begin{array}{l}\text { Concerning communication between } \\
\text { management and employees }\end{array}$ & $\begin{array}{l}\text { No interaction between management and workforce with the } \\
\text { focus on influencing working issues or decision within the firm }\end{array}$ \\
\hline
\end{tabular}

Source: author 
After having checked whether the inclusion criteria were correctly applied, we then applied the exclusion criteria that each article fell within the conceptual boundaries established. A total of 60 articles were deemed relevant following this process. At this stage a thorough review of the full article was conducted by the author and a research colleague and the articles classified into one of five categories (Macpherson and Holt 2007): primary, secondary, peripheral, conceptual and not relevant per the criteria in Table 3. It is important to note that the paper categorization at this stage was not a stand-alone judgment of the study's quality but of its fit with the review criteria, i.e. empirical research on EIP practice in SMEs. Judgements were made particularly on whether there was an indication that the article included theories and findings that were directly related to EIP which contribute to policy and practice. Those articles that were highly relevant in the majority of criteria were judged as primary data, those with a majority of medium relevance in the criteria were categorized as being of secondary relevance, etc. Articles that concentrated on one specific EIP practice, such as H\&S representatives (Walters 1998a, b; 2004; Frick and Walters 1998), collective representation in SMEs (Haynes et al. 2006; Moore and Read 2006; Helfen and Schuessler 2009) or employee suggestion schemes (Andries and Czarnitzki 2014) could still be of primary relevance as long as they reviewed explicitly the extant theory on the specific EIP practice(s) under investigation and the findings had a clear utility for EIP practice and policy. Articles that crossed several themes associated with EIP, e.g. EIP practices being a part of lean management practices, Total Quality Management (TQM) or as an element within high performance work systems (HPWS) were more likely to be considered as not being of primary relevance due to the primary focus on theories/concepts related to TQM, lean management, HPWS or general management in HRM rather than EIP 
specifically. There were 28 articles categorized as being of primary relevance, seven as being of secondary relevance, 24 of peripheral relevance, none as irrelevant and one conceptual paper. The full text of the 28 studies initially categorized as primary were then analysed using an Excel spreadsheet to code and identify themes to form the basis of this review. This spreadsheet can be provided by the author on request.

Table 2. Relevance assessment criteria and the categorization of articles

\begin{tabular}{|c|c|c|c|c|}
\hline \multicolumn{5}{|c|}{ Relevance assessment criteria } \\
\hline Aspect of study & $0=$ absent & 1: low & 2: medium & 3: high \\
\hline $\begin{array}{l}\text { Theoretical } \\
\text { contribution and } \\
\text { insight }\end{array}$ & $\begin{array}{l}\text { Insufficient } \\
\text { information to assess } \\
\text { this criterion }\end{array}$ & $\begin{array}{l}\text { Weak development of } \\
\text { theoretical insights } \\
\text { and limited awareness } \\
\text { of prevailing literature }\end{array}$ & $\begin{array}{l}\text { Basic development of } \\
\text { theory and use of } \\
\text { concepts gathered } \\
\text { from existing } \\
\text { literature }\end{array}$ & $\begin{array}{l}\text { Good use of theory, } \\
\text { including the novel } \\
\text { and provocative } \\
\text { development of } \\
\text { concepts }\end{array}$ \\
\hline $\begin{array}{l}\text { Embeddedness in } \\
\text { practice }\end{array}$ & $\begin{array}{l}\text { Insufficient } \\
\text { information to assess } \\
\text { this criterion }\end{array}$ & $\begin{array}{l}\text { Hard to use the } \\
\text { concepts and ideas in } \\
\text { EIP application }\end{array}$ & $\begin{array}{l}\text { Findings have } \\
\text { potential utility for } \\
\text { business and policy } \\
\text { makers }\end{array}$ & $\begin{array}{l}\text { The utility for } \\
\text { practitioners and } \\
\text { policy makers is clear }\end{array}$ \\
\hline $\begin{array}{l}\text { Methodology and } \\
\text { methods - data } \\
\text { supporting } \\
\text { arguments }\end{array}$ & $\begin{array}{l}\text { Insufficient } \\
\text { information to assess } \\
\text { this criterion }\end{array}$ & $\begin{array}{l}\text { Incomplete data and } \\
\text { not related to theory } \\
\text { coupled to weak } \\
\text { research design }\end{array}$ & $\begin{array}{l}\text { Data broadly related } \\
\text { to the arguments, and } \\
\text { conveyed through a } \\
\text { clear research design } \\
\text { and method }\end{array}$ & $\begin{array}{l}\text { Data strongly } \\
\text { supports arguments. } \\
\text { Robust research } \\
\text { design and good use } \\
\text { of methods }\end{array}$ \\
\hline $\begin{array}{l}\text { Relevance of three } \\
\text { areas: findings, } \\
\text { theories; methods }\end{array}$ & $\begin{array}{l}\text { Insufficient } \\
\text { information to assess } \\
\text { this criterion }\end{array}$ & $\begin{array}{l}\text { Only tangentially } \\
\text { relevant; provocative } \\
\text { but linked to an } \\
\text { established line of } \\
\text { thought }\end{array}$ & $\begin{array}{l}\text { Broadly relevant - } \\
\text { perhaps in one of the } \\
\text { areas, or applied in } \\
\text { different disciplinary } \\
\text { fields }\end{array}$ & $\begin{array}{l}\text { Integration of } \\
\text { findings, methods and } \\
\text { theoretical constructs }\end{array}$ \\
\hline Contribution & $\begin{array}{l}\text { Insufficient } \\
\text { information to assess } \\
\text { this criterion }\end{array}$ & $\begin{array}{l}\text { Insignificant } \\
\text { contribution; it is not } \\
\text { clear the advances it } \\
\text { makes }\end{array}$ & $\begin{array}{l}\text { Although using } \\
\text { other's ideas, builds } \\
\text { upon the existing } \\
\text { theory }\end{array}$ & $\begin{array}{l}\text { Further develops } \\
\text { existing knowledge, } \\
\text { expanding issues }\end{array}$ \\
\hline
\end{tabular}

Source: Macpherson and Holt, 2007, adapted by author 
Table 3. Categorization of articles

\begin{tabular}{|c|c|l|}
\hline Categorization & Criteria & \multicolumn{1}{c|}{ Criteria - guidance } \\
\hline primary & majority "3" & $\begin{array}{l}\text { Studies that indicate a high level of coherence and } \\
\text { contribution were considered directly related to the study } \\
\text { criteria }\end{array}$ \\
\hline secondary & majority "2" & $\begin{array}{l}\text { Information on only theory or findings and/or the relevance } \\
\text { to policy and practice was ambiguous }\end{array}$ \\
\hline peripheral & majority "1" & $\begin{array}{l}\text { Theories and concepts that were tangential or not clearly } \\
\text { linked to EIP in SMEs and/or findings were unrelated to } \\
\text { policy and practice }\end{array}$ \\
\hline not relevant & majority "0" & $\begin{array}{l}\text { Theories and concepts that were not linked to EIP in SMEs } \\
\text { or findings were unrelated to policy and practice }\end{array}$ \\
\hline
\end{tabular}

Source: author

\section{Literature review: findings}

Scholarly interest in EIP in SMEs took off in the late 90s as seen in the steady contributions to EIP in SMEs research published in peer-reviewed, academic journals. Following the Academic Journal Guide 2015 (CABS 2015) one article appeared in a one rated journal and seven articles were published in two rated journals, which are general seen as publishing original research of acceptable standards with many excellent practitioner-oriented articles published there. Another 12 articles appeared in three rated journals and six articles in four rated journals. Both journal categories publish original and well executed research. Two journals were not included in the Journal Guide 2015 (Figure 1).

The quality of journals is related to the method applied (Figure 1). Quantitative and mixed method studies dominate the work published in the higher quality rated journals indicating a preference for quantitative work. This shift towards quantitative orientation in EIP research in SMEs is supported by a few other factors pushing in this direction, including the rising opinion 
among researchers that the main journals in their field favour quantitative pieces (Whitfield and Strauss 2000). Nevertheless, the review shows that at present room remains for genuine qualitative research to be published in quality rated journals. Policy makers and managers have always used a wide range of sources of evidence in making decisions about policy and the organization of the business. However, they are coming under increasing pressure to adopt systematic, thorough and seemingly objective evidence to address complicated questions about the nature and significance of the problem, the nature of proposed actions and their differential impact, cost-effectiveness, acceptability etc. Qualitative research is primarily exploratory research to gain an understanding of a phenomenon or to dive deeper into the problem, since the sample size is typically small. Hence the researchers' ability to generalization from the findings remains often limited. Policy makers and practitioners rather require access to research that emphasize objective measurements and the greater relevance of statistical, mathematical or numerical analysis of data leading to demand for more quantitative or mixed studies. This tendency is reflected in our review since the articles identified are classified according to the contributions' embeddedness in practice and its utility for practitioners and policy-makers.

Figure 1. Distribution of articles by method and journal rating

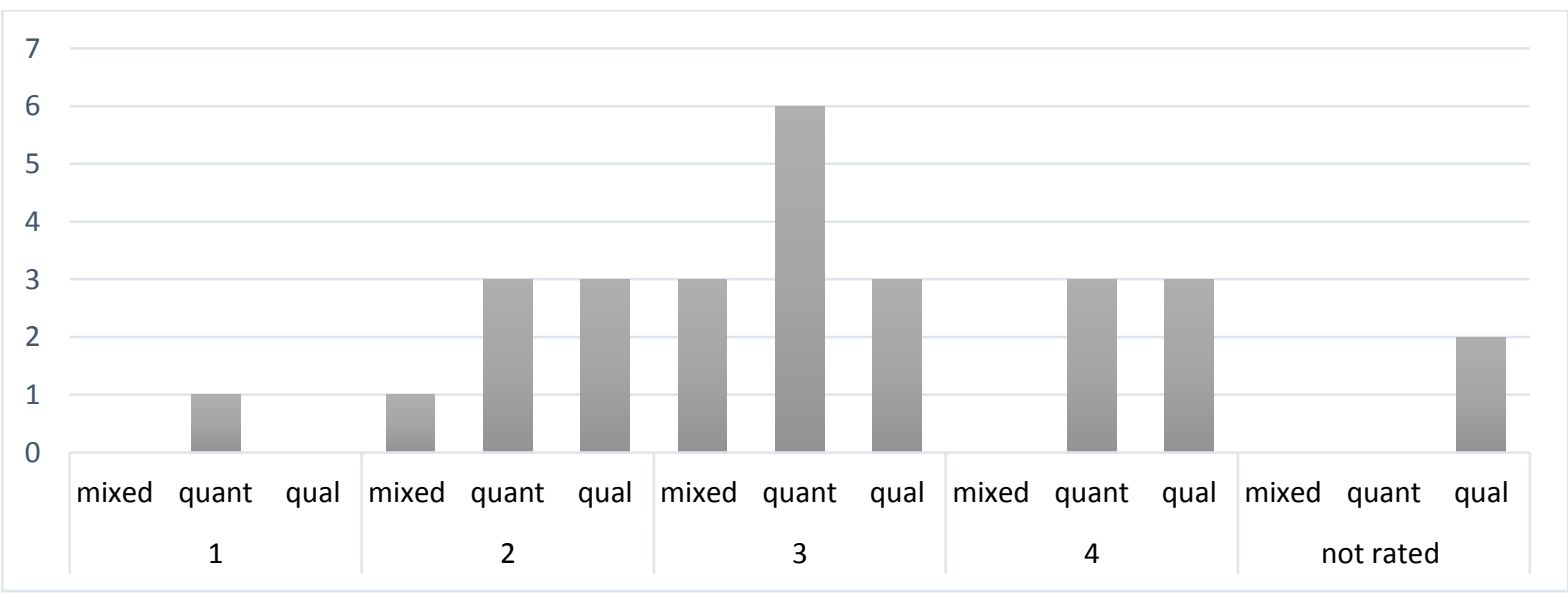

Source: author 
EIP research in SMEs is published in a wide variety of subject areas that are identified by the ABS Academic Journal Guide 2015 (Figure 2). Journals in "HRM and employment studies" tend to cluster most research on EIP in SMEs $(n=19)$ and only a small part of research is published in "entrepreneurship and small business management" $(\mathrm{n}=3)$. This tendency may not only indicate the relative nascence of research focusing on HRM issues in SMEs, a fertile ground for research that has been overlooked (Katz et al. 2000; Moore and Read 2006). Positioning an EIP paper for submission to a general SME management journal also requires a different approach. Rather than leading with an emphasis on filling a gap in the HRM literature, it is important to identify the shortcomings in existing management debates and research that looks at social relations, on which recourse to an SME context helps shed new light. An approach which EIP researchers appear to have hardly pursued and if so then only more recently (Dietz et al. 2006; Uhlaner et al. 2013 and Andries and Czarnitzki 2014). However, it hinders the dissemination of quality research into broader management circles which could fertilize and support EIP research given its demonstrated relevance for management decision-making and organizational performance and the multidisciplinary nature of EIP research (Wilkinson et al. 2014).

Figure 2. Journals according to areas according to the ABS AJR 2015

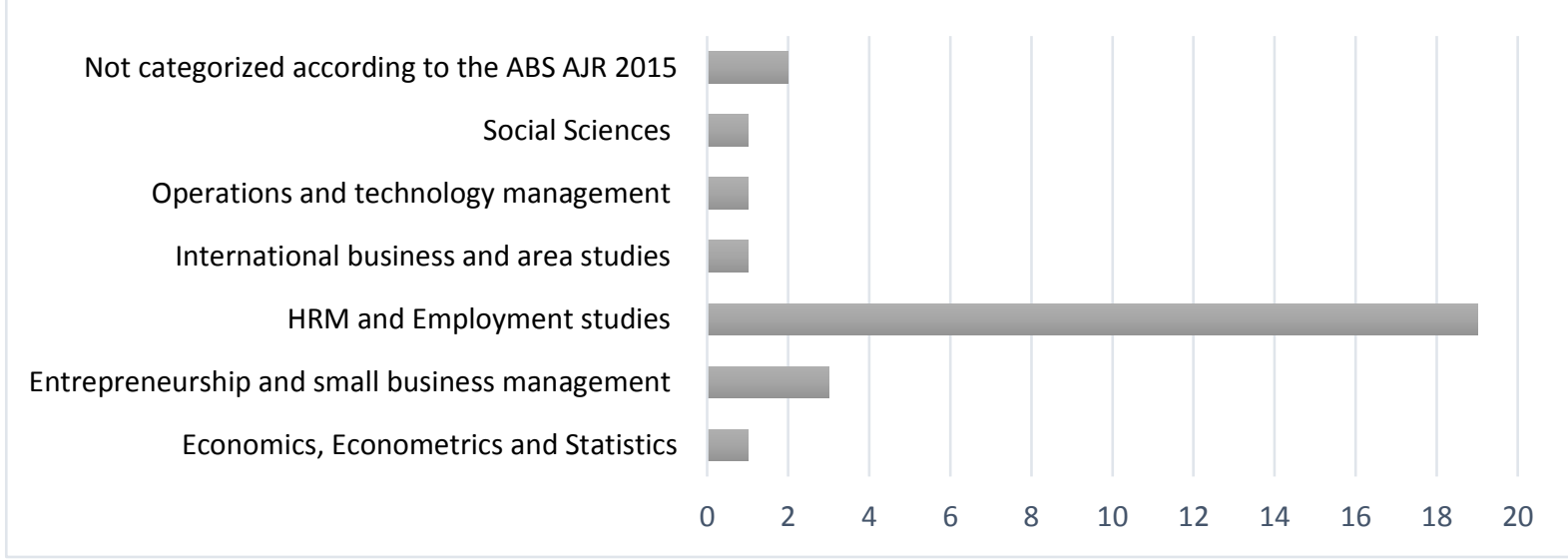

Source: author 
Focusing on the setup of the research framework the large majority of studies adopts a single country focus ( $n=24)$. Moreover, Anglo-Saxon countries $(n=16)$, in particular the UK $(n=11)$ as well as European countries $(\mathrm{n}=13)$, with a dominance of Germany and the EU as a region ( $n=3$ each), are the principal foci in extant research. One study does not even allow the reader identifying the specific country setting in which the empirical data was collected (Allen et al. 2013). Hence EIP research in SMEs is dominated by empirical knowledge generated in AngloSaxon and Western European countries. It reveals that the Middle East, Africa, Latin America and Asia constitute severely understudied and underrepresented geographies in research. Hence EIP research conducted outside Western Europe and Anglo-Saxon countries does not sufficiently inform theory making in EIP research in SMEs and demarks knowledge and imagination of EIP practices to those geographies studied (Özbilgin 2004), the lack of multinational studies ( $\mathrm{n}=3$ in our sample) even across Western European countries implies a difficulty of formulating overarching conceptual frameworks, theoretical models in EIP. The former is lamentable since Blasi et al. (2003), Walters (2004) and Gilman and Raby (2013) show in their empirical studies that idiosyncrasies attached to specific national, often institutional, context engender and influence EIP practice in SMEs. The latter point is a supporting factor that EIP in SMEs remains an under-theorized and under-researched area (Gilman et al. 2015).

While the literature on EIP finds its roots in several disciplines and therefore gaining insights from complementary and competing approaches towards EIP (Wilkinson et al. 2014), our analysis shows that EIP research in SMEs lacks this attribute. Following the categorization by Wilkinson, and colleagues (2014) the large majority of studies are rooted in the HRM/HPWS literature $(n=22)$. While this is not surprising given the dominant journal category of "HRM 
and employment studies" in which articles are published, it brings to light that extant SME research on EIP lacks "the potential for greater theoretical specificity within the wide range of perspectives that shape understanding and can help identify conceptual overlap" between different theoretical strands (Wilkinson et al. 2014, 9).

A related point arises with respect to the meaning of EIP (Dundon et al. 2004). A large majority of studies $(\mathrm{n}=22)$ captures EIP in an SME context as contribution to management decisionmaking (Dundon et al. 2004, 1152). Here EIP research is informed by the underlying assumption that EIP helps employees gaining input to improve work organization and efficiency more generally, particularly through management initiatives such as upward problem-solving practices or by eliciting workforce engagement, leading to "high levels of energy that are invested in work" (Hallberg and Schaufeli 2006, 119; Wilkinson et al. 2013). Already Strauss $(2006,778)$ denoted, facilitating EIP “provides a win-win solution to a central organizational problem - how to satisfy workers' needs while simultaneously achieving organizational objectives". However, theory and practice can diverge (Harley et al. 2005) and EIP research requires a more critical approach in analysis by interrogating the multiple views by stakeholders. While nine studies in our analysis base their findings on management responses only, i.e. those who adapt, interpreted and implement legislation and corporate initiatives, an equal part of enquiries solicits either the employee perspectives $(n=1)$, collects information on EIP from multiple stakeholders $(n=3)$ or interrogates management and employees alike $(n=5)$ and therefore provides differing views on how EIP is perceived. A further four studies did not provide information on their unit of analysis.

Following the categorisation by Marchington and Wilkinson (2005) we also observe that research on EIP covers the whole range of EIP techniques (Figure 3). Taking downward 
communication and upward problem-solving together, direct EIP $(n=18)$ is equally investigated as is representative participation $(n=17)$ followed by financial participation $(n=12)$. Three studies focus on EIP in general without breaking it down further into specific techniques and two studies use other concepts to operationalize EIP in their enquiry. These findings are interesting given the observed trend in the general literature towards direct individual voice mechanisms rather than participative representation (Brewster et al. 2007). Furthermore, of the categorized research, 12 studies focus on a single EIP technique in specific country contexts only, providing limited insight into the comparative differences and their wider integration and synergies between EIP techniques.

Figure 3. Different types of EIP

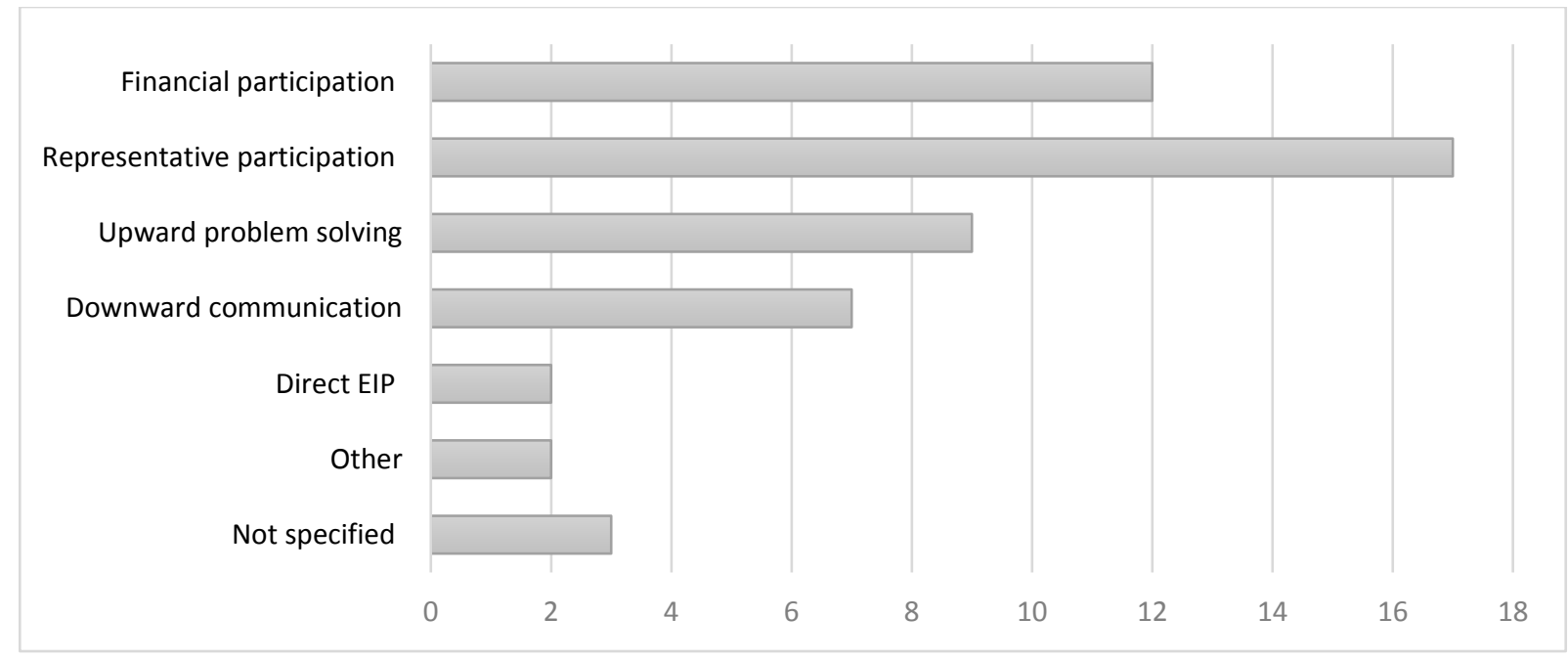

Source: author

With respect to external influences and internal dynamics for EIP practice, all studies contextualize their findings to the SME context. While 12 studies refer to the SME context in general, in eight articles explicit SME size groups are identified. Nine studies in total include a comparison amongst differently sized companies, mainly including a comparison between SMEs and large organizations rather than between differently sized SMEs. The fact that there 
is very little research that differentiates between different SME size groups calls attention since a few researchers (Uhlander et al. 2013; Della Torre and Solari 2013; Moore and Read 2006; Cox et al. 2009; Bayo-Morines and Larraza-Kintana 2009) show that variations in EIP within SMEs of different size exist. Uhlander and colleagues $(2013,605)$ accentuate "that even among SMEs, there is major difference between the management of the very small ( $<10$ employees) and even moderately small (i.e. between 50 and 100 employees) firms, a difference that has not been adequately addressed in the literature."

To test whether authors contextualize beyond the mere size variable we compared their research findings on influential factors for EIP practice with the open systems HRM framework for SMEs developed by Harney and Dundon (2006). Their framework to analyse HRM in SMEs conceptualises a complex interplay of external structural factors and internal dynamics. In fact, all researchers acknowledged that research which considers SMEs in isolation is ultimately misleading (Barrett and Rainnie 2002; Cassell et al. 2002). Most researchers $(n=20)$ contextualizes according to a mix of external influences and internal dynamics, given that small firms have less control over their environment than larger organizations. The remaining studies $(n=8)$ refer to internal dynamics only. Among the most prominent factors that influence EIP practice in SMEs are trade union presence or absence $(n=17)$, management style and ideology $(n=15)$, legislation $(n=13)$, employee characteristics, industry sector and product/market structure $(\mathrm{n}=9$ each). Moreover, many studies $(\mathrm{n}=18)$ identified a range of additional factors that were found relevant. Among the most frequently used additional factors to influence EIP were the presence of the HR specialist/unit $(n=3)$, firm age $(n=4)$, nature of social relations $(n=3)$ and firm's competitive strategy $(n=3)$. Extant research therefore underlines the importance of context for employers' choices of EIP regimes (Marchington 2007) but also the 
challenges for the employer and employee side to assess and develop a fitting EIP framework for the greatest organizational impact and employee good.

Finally, except for two studies, the large majority of studies were based on cross-sectional data $(n=26)$. Hence changes over time in EIP practice, long term effects of EIP practices nor the varying impact of factors over time are hardly assessed.

\section{Discussion and Conclusion}

In a nutshell, the systematic review on the EIP literature in SMEs not only demonstrates the key patterns of EIP research in SMEs with respect to its methodology and thematic content. It also sets out the background against which future empirical enquiry can be conducted and we perceive the following three research lines to be particularly fruitful.

First, to enrich the conceptual underpinning of EIP research, we see the need to adopt a multiple country focus drawing on management and employee data. Such research framework allows the identification and analysis of idiosyncrasies and commonalities that drive formal EIP and that steam from different national, institutional contexts. As Gilman and Raby $(2013,385)$ observe for HPWS including EIP practices, "attention must be placed not solely at the organizational level but also at the institutional level". Confirming this observation, our review systematically identified the range of factors beyond the boundaries of the firm that moderate firm EIP practice in SMEs, extending the open systems HRM framework for SMEs by Harney and Dundon (2006). However, at present we do not know about the overarching relevance of these factors across different national contexts and their complex factor interactions within national boundaries, which has been cited as theoretically weak in much of the extant literature on SMEs (Barret and Rainnie 2002, 416; Harney and Dundon 2006). 
Such comparative analysis of external factors and internal influences driving EIP in SMEs would be valuable for practitioners as well. It is accepted that the behaviour of organisations cannot just be considered as a response to economic downturns and market pressure but also to their embeddedness in wider social and institutional environments that require differentiated management responses, particularly when organizing an SME internationally. Management practices, including EIP, reflect the rules, norms and structures prevalent in their societal setting, as shown by the cross-country study by Gilman and Raby (2013).

Considering institutional factors in more detail, our review of the literature has shown that research repeatedly points to the influence of employment law. Of more recent significance is here the European Information and Consultation of Employees 2004 Regulation that came in effect in 2008 for SMEs. For the first time, employees across Europe in SMEs above the 50employee threshold have the legal right to be informed and consulted on a range of business and employment matters, should they wish (Wilkinson et al. 2007). However, its impact in specific countries is ambiguous (for the UK: Wilkinson et al. 2007; Cox et al. 2009) and may exercises little pressure on management for conformity (for Germany: Helfen and Schuessler 2009). It means that there remains leeway for SMEs to cope with institutional pressure and managers have certain choice in the adoption of the EIP practices. Most empirical studies usually show a myriad of EIP techniques in SMEs (Wilkinson et al. 2013) which are shaped by external and internal contingencies (Gilman and Raby 2013; Gilman et al. 2015; Wilkinson et al. 2007; Dietz et al. 2006) but practitioners are often left alone to identify the commonalities among these contingencies that drive EIP practice and influence its outcomes. Given that causalities cannot be attributed in a linear fashion within such a complex system of social and institutional environments, the emphasis on operationalising the context for EIP should not be 
on prediction but rather understanding what is contextually significant and unique and the reason for it (Brewster 1999; Truss 2002). This would allow a more informed management choice on EIP practice implementation to fit a given business contexts. Combining such research with a size sensitive research framework within the SME group could also encourage a better fit with the management literature configuring management theory further to differing SME national and organizational contexts.

Secondly, longitudinal research that examines how EIP practices in SMEs have changed over time is of merit for the conceptual development in EIP. This is of interest in current times, as in 2008 the most serious crisis to hit the global economy since the Great Depression began in the US and spread rapidly to Europe. Hence a pre, after and during crisis examination would help understand how an economic downturn has affected organizations and, ideally, the EIP prospects for workers in different institutional contexts. It might be that new forms of EIP emerged or vanished during different periods, sometimes replacing and at other times coexisting with prior forms of participation. Such interrogation could lead to a more thorough evaluation of the antecedence and drivers of EIP practice in SMEs to explain further why EIP is different to large organization. While research exists in this respect to large organisations, such systematic investigation is missing at present, even though McMahon underlined earlier on that

"[...] while the internal and external factors identified are identical to those affecting large firms, given SMEs' proximity to the external environment, it is 'the way in which these factors impact on small firms that makes the situation for small firms different from that of large firms."

(McMahon 1995, 199; original emphasis, cited by Harney and Dundon 2006).

Finally, EIP research in SMEs focuses to equal parts on participation and involvement, which is surprising given the present managerial rhetoric and SMEs being commonly classified as 
non-union firms. However, collective participation is a broad term and more detailed case study evidence is needed to see whether this indicates a shift towards more managerially-driven forms (Brewster 2007). While extant research investigates employees' attitudes towards EIP or trade unions, skills levels, ethnicity and income levels, further case study research should also try to identify common responses to EIP practices by groups of employees that share specific characteristics.

To conclude, this article makes an important contribution to the existing literature on EIP in SMEs by providing a transparent and objective assessment of extant EIP research. While the descriptive and thematic analysis has shown the evolution and state-of-art in EIP research, further advances can be made to improve the field further and eventually help positioning an EIP article for submission to a general SME management journal with the benefit to reach broader audiences. Cross-country, longitudinal studies of EIP including qualitative studies that incorporate a differentiation according to size within the SME group are seen as particularly promising to overcome existing limitations and to advance the field in this respect.

\section{Acknowledgements}

This project has received funding from the European Union's Horizon 2020 research and innovation programme under the Marie Sklodowska-Curie grant agreement No 734447. Also, I am grateful to my collaborating research colleagues (Carlos Salvador Muñoz and Alesia Slocum) for their comments. 


\section{References}

Allen, Mathew R., Jeff Ericksen, and Christopher J. Collins. (2013). "Human Resource Management, employee exchange relationships, and performance in small businesses." Human Resource Management 52 (2): 153-174.

Andries, Petra, and Dirk Czarnitzki. (2014). "Small firm innovation performance and employee involvement." Small Business Economics 43 (1): 21-38.

Antcliff, Valerie, and Richard Saundry. 2009. "Accompaniment, workplace representation and disciplinary outcomes in British workplaces - just a formality?" British Journal of Industrial Relations 47 (1): 100-21.

Barrett, Rowena, and Susan Mayson. 2007. "Human resource management in growing small firms." Journal of Small Business and Enterprise Development 14 (2): 307-20.

Barrett, Rowena, and Al Rainnie. 2002. "What's so special about small firms. Developing an integrated approach to analysing small firm industrial relations." Work Employment and Society 16 (3): 415531.

Bayo-Moriones, Alberto, and Martin Lazarra-Kintana. 2009. "Profit-sharing plans and affective commitment: does the context matter?" Human Resource Management 48 (2): 207-226..

Blasi, Joseph, Douglas Kruse, James Sesil and Maya Kroumova. 2003. "An assessment of employee ownership in the United States with implications for the EU." International Journal of Human Resource Management 14 (6): 893-919.

Brewster, Chris. 1999. "Strategic human resource management: the value of different paradigms." Management International Review 39 (3): 45-64.

Brewster, Chris. 2007. "Comparative HRM: European views and perspectives." International Journal of Human Resource Management 18 (5): 769-87.

Brewster, Chris, Richard Croucher, Geoff Wood, and Michael Brookes. 2007. "Collective and individual voice: convergence in Europe?" International Journal of Human Resource Management 18 (7): 1246-62.

Briner, Rob and David Denyer. 2012. "Systematic review and evidence synthesis as a practice and scholarship tool." In Oxford handbook of evidence-based management, edited by Denise M. Rousseau, 112-29. Oxford: OUP.

Bryson, Alex, Rafael Gomez, Tobias Kretschmer, and Paul Willman. 2007. "The diffusion of workplace voice and high-commitment human resource management practices in Britain, 1984-1998." Industrial and Corporate Change 16 (3): 394-426. 
CABS. 2015. "Academic Journal Guide." The Chartered Association of Business Schools. Accessed July 5, 2016. https://charteredabs.org/academic-journal-guide-2015/,

Cassell Catherine, Sara Nadin, Melanie Gray, and Chris Clegg. 2002. "Exploring human resource management practices in small and medium sized enterprises." Personnel Review 31 (5/6): 671692.

Castrogiovanni, Gary J. 2011. "The role of human capital factors in small business performance and success." In Human Resource Management in Small Business, edited by Cary L. Cooper and Ronald J. Burke, 71-92. Cheltenham: Edgar Elgar.

Cox, Annette, Mick Marchington, and Jane Suter. 2009. "Employee involvement and participation: developing the concept of institutional embeddedness using WERS 2004". International Journal of Hunan Resource Management 20 (10): 2150-2169.

Della Torre, Edoardo, and Luca Solari. 2013. "High-performance work systems and the change management process in medium-sized firms." The International Journal of Human Resource Management 24 (13): 2583-2607.

Diez, Graham, Ton van der Wiele, Jos van Iwaarden and Julie Brosseau. 2006. "HRM inside UK-ecommerce firms: innovations in the 'new' economy and continuities with the 'old'. International Small Business Journal 24 (5): 443-470.

Dundon, Tony, Andrew Wilkinson, Mick Marchington, and Paul Ackers. 2004. "The meanings and purpose of employee voice." International Journal of Human Resource Management 15 (6): 1149-70.

Eurofound. 2015. “Third European Company Survey - Overview, report: workplace practices patterns, performance and well-being." Luxembourg: Publication of the European Union.

Frick, Kaj, and David Walters.1998. "Worker representation on health and safety in small enterprises: lessons from a Swedish approach." International Labour Review 137 (3): 367-389.

Fulton, Lionel. 2013. "Workplace representation in Europe." Labour Research Department and ETUI. Accessed June 13, 2016. http://www.worker-participation.eu/National-IndustrialRelations/Across-Europe/Workplace-Representation2.

Gilman, Mark, and Simon Raby. 2013. "National contexts as a predictor of high-performance work system effectiveness in small-to-medium-size enterprises (SMEs): a UK-French comparative analysis." The International Journal of Human Resource Management 24 (3): 372-390.

Gilman, Mark, Simon Raby, and Amanda Pyman. 2015. "The contours of employee voice in SMEs: the importance of context." Human Resource Management Journal 25 (4): 563-79.

Gough, David, James Thomas, and Sandy Oliver. 2012. "Clarifying differences between review designs and methods." Systematic Reviews 1 (28): 1-9. 
Guest, David. 1998. "Is the psychological contract worth taking seriously?" Journal of Organizational Behaviour 19 (S1): 649-64.

Hallberg, Ulrika, and Wilmar B. Schaufeli. 2006. “"The same” but different?" European Psychologist $11(2): 119-27$.

Harley, Bill, Jeff Hyman, and Paul Thompson, eds. 2005. Participation and Democracy at Work: essays in Honour of Harvie Ramsay. Basingstoke: Palgrave Macmillan.

Harney, Brian, and Dundon, Tony. 2006. "Capturing complexity: developing an integrated approach to analyzing HRM in SMEs." Human Resource Management 16 (1): 48-73.

Haynes, Peter, Peter Boxall, and Keith Macky. 2006. "Union reach, the 'representation gap' and the prospects for unionism in New Zealand.” Journal of Industrial Relations 48 (2): 193-216.

Hayton, James C. 2004. "Strategic human capital management in SME's: an empirical study of entrepreneurial performance." Human Resource Management 42 (4): 375-91.

Helfen, Markus, and Elke S. Schuessler. 2009. "Uncovering divergence: management attitudes towards HRM practices and works council presence in German SMEs." Economic and Industrial Democracy 30 (2): 207-240.

Katz, Jerome A., Howard E. Aldrich, Theresa M. Welbourne, and Paul M. Williams.. 2000. "Guest Editor's Comments Special Issue on Human Resource Management and the SME: Toward a New Synthesis." Entrepreneurship: Theory and Practice 25 (1): 7-26.

Katzenbach, Jon R. 2000. Peak performance: aligning the hearts and minds of your employees. Boston: Harvard Business School Press.

Macpherson, Allan, and Robin Holt. 2007. "Knowledge, learning and small firm growth: a systematic review of the evidence." Research Policy 36 (2): 172-92.

Marchington, Mick. 2015. "Analysing the forces shaping employee involvement and participation (EIP) at organization level in liberal market economics (LMEs)." Human Resource Management Journal 25 (1): 1-18.

Marchington, Mick. 2007. “Foreword.” Human Resource Management Journal 18 (1-2): 1-2.

Marchington, Mick, and Adrian Wilkinson. 2005. "Direct participation and involvement." In Personnel Management in Britain (4 ${ }^{\text {th }}$ edition), edited by Stephen Bach, 398-423. Oxford: Blackwell.

Marchington, Mick, and Jane Suter. 2013. "Where informality really matters: patterns of employee involvement and participation (EIP) in a non-union firm." Industrial Relations 52 (S1): 284-313.

Moore, Sian, and Ian Read. 2006. "Collective organization in small- and medium-sized enterprises - an application of mobilization theory." Human Resource Management Journal 16 (4): 357-375.

Nolan, Ciara. T., and Thomas N. Garavan. 2015. "Human Resource Development in SMEs: A systematic review of the literature.” International Journal of Management Review 18 (1): 85-107. 
Özbilgin, Muhammed. 2004. "International" human resource management. Academic parochialism in editorial boards of the top 22 journals on international human resource management." Personnel Review 33 (2): 205-21.

Peccei, Riccardo, Helen Bewley, Howard Gospel, and Paul Willman. 2010. "Antecedents and outcomes of information disclosure to employees in the UK 1990-2004: the role of employee voice." Human Relations 63 (3): 419-38.

Pyman, Amanda, Brian Cooper, Julian Teicher, and Peter Holland. 2006. "A comparison of the effectiveness of employee voice arrangements in Australia." Industrial Relations Journal 37 (5): 543-59.

Pyman, Amanda, Peter Holland, Julian Teicher, and Brian Cooper. 2010. "Industrial relations climate, employee voice and managerial attitudes to unions: an Australian study." British Journal of Industrial Relations 48 (1): 460-80.

Richardson, Mike, Andy Danford, Paul Steward, and Valeria Pulignano. (2010). "Employee participation and involvement: experiences of aerospace and automobile workers in the UK and Italy." European Journal of Industrial Relations 16 (1): 21-37.

Sameer, Muhammad, and Mustafa F. Özbilgin. 2014. "Employee voice in the SME context." In Handbook of research on employee voice, edited by Adrian Wilkinson, Jimmy Donaghey, Tony Dundon, and Richard B. Freeman, 410-20. Northampton: Edward Elgar.

Schwartz, Tony. 2010. The way we are working, isn't working. New York: Free Press.

Strauss, George. 2006. "Worker participation - some under-considered issues." Industrial Relations 45 (4): 778-803.

Townsend, Keith, Adrian Wilkinson, and John Burgess. 2012. "Filling the gaps: patters of formal and informal participation." Economic and Industrial Democracy 34 (2): 337-354.

Tranfield, David, David Denyer, and Palminder Smart. 2003. "Towards a methodology for developing evidence-informed management knowledge by means of systematic review." British Journal of Management 14 (2): 207-22.

Truss, Catherine. 2002. "Shifting the paradigm in human resource management: from the resource base view to complex adaptive systems." Research Papers in Human Resource Management, Kingston Business School, Accessed July 29, 2016. http://citeseerx.ist.psu.edu/viewdoc/download?doi=10.1.1.321.7149\&rep=rep1\&type=pdf.

Uhlaner, Lorraine, Andre van Stel, Valerie Duplat, and Haibo Zhou. (2013). „Disentangling the effects of organizational capabilities, innovation and firm size on SME sales growth." Small Business Economics 41 (3): 581-607.

Ulrich, Dave, and Wendy Ulrich. 2010. The why of work. New York: McGraw Hill. 
Walters, David. 1998a. "Employee representation on health and safety in small enterprises." Employee Relations 20 (2): 164-179.

Walters, David. 1998b. "Employee representation and health and safety." Employee Relations 20 (2): 180-195.

Walters, David. 2004. "Worker representation and health and safety in small enterprises in Europe." Industrial Relations Journal 25(2): 169-186.

Whitfield, Keith, and George Strauss. 2000. "Methods matter: changes in industrial relations research and their implications." British Journal of Industrial Relations 38 (1): 141-51.

Wilkinson, Adrian, Tony Dundon, and Irina Grugulis. 2007. "Information but not consultation: exploring employee involvement in SMEs." International Journal of Human Resource Management 18 (7): 1279-1297.

Wilkinson, Adrian, Tony Dundon, and Mick Marchington. 2013. "Employee involvement and voice." In Managing Human Resources, edited by Stephen Bach, and Martin Edwards, 268-88. Oxford: Blackwell.

Wilkinson, Adrian, Tony Dundon, Jimmy Donaghey, and Richard B. Freeman. 2014. "Employee voice: charting new terrain." In Handbook of research on employee voice, edited by Adrian Wilkinson, Jimmy Donaghey, Tony Dundon, and Richard B. Freeman, 3-16. Northampton: Edward Elgar.

Wilkinson, Adrian, Paul J. Gollan, Mick Marchington, and David Lewin. 2010. "Conceptualizing employee participation in organizations." In Oxford handbook of participation in organizations, edited by Paul J. Gollan, David Lewin, Mick Marchington, and Adrian Wilkinson. Oxford: OUP. Wilkinson, Adrian, Mick Marchington, and Paul Ackers. 2004. "Changing patterns of employee voice.” Journal of Industrial Relations 46 (3): 298-322.

Wood, Steven, and Mark P. Fenton O'Creevy. 2005. "Direct involvement, representation and employee voice in UK multinationals in Europe.” European Journal of Industrial Relations 11 (1): 27-50.

This is an Open Access article distributed under the terms of the Creative Commons Attribution-Non-Commercial-No Derivatives License (http://creativecommons.org/licenses/by-nc-nd/4.0/), which permits non-comercial re-use and distribution, provided the original work is properly cited, and is not altered or transformed in any way. 